\title{
Commentary: Nomogram to the rescue: Validate and show me the money
}

\author{
Richard S. Lazzaro, MD, FACS, and \\ Matthew L. Inra, MD
}

Clinical staging accuracy for esophageal cancer is limited. Different methods of $\mathrm{T}$ staging-magnetic resonance imaging, computed tomography, and endoscopic ultrasound (EUS) - have been compared ${ }^{1}$ and there is no perfect method. Mehta and colleagues ${ }^{2}$ from the University of Pittsburgh reported that EUS accurately staged just $39 \%$ of T1a lesions and $70 \%$ of $\mathrm{T} 1 \mathrm{~b}$ lesions. Bergeron and colleagues ${ }^{3}$ at the University of Michigan reported that only $39 \%$ of $\mathrm{T} 1 \mathrm{a}$ lesions and $51 \%$ of $\mathrm{T} 1 \mathrm{~b}$ lesions were correctly staged using EUS. Additionally, $\mathrm{N}$ staging is not always accurate either. The University of Michigan study showed that lesions thought to be cT1aN0 using EUS turned out to be pN1 or higher in $15 \%$ of patients. ${ }^{3}$ The T stage can often predict the probability of having lymph node metastases, but not always and "patients with occult lymph node metastases have worse prognosis than those without" as stated by Yun and colleagues. ${ }^{4}$ Consequently, actions to improve or supplement the accuracy of clinical staging merit consideration to appropriately select patients for upfront surgery or induction therapy as per established treatment guidelines.

In this issue of the Journal, Yun and colleagues ${ }^{4}$ present a scoring system and nomogram to help predict occult lymph node metastases in patients with esophageal squamous cell carcinoma who have undergone guideline-based clinical staging. The authors identify tumor characteristics—-standard

\footnotetext{
From the Department of Cardiovascular and Thoracic Surgery, Northwell Health Lenox Hill Hospital, New York, NY; and Donald and Barbara Zucker School of Medicine at Hofstra Northwell, Hempstead, NY.

Disclosures: The authors reported no conflicts of interest.

The Journal policy requires editors and reviewers to disclose conflicts of interest and to decline handling or reviewing manuscripts for which they may have a conflict of interest. The editors and reviewers of this article have no conflicts of interest.

Received for publication Oct 24, 2021; revisions received Oct 24, 2021; accepted for publication Oct 25, 2021; available ahead of print Oct 28, 2021.

Address for reprints: Richard S. Lazzaro, MD, FACS, Department of Cardiovascular and Thoracic Surgery, Northwell Health Lenox Hill Hospital, 130 East 77th St, 4th Floor - Black Hall, New York, NY 10075 (E-mail: rlazzaro@northwell.edu).

J Thorac Cardiovasc Surg 2022;164:276-7

$0022-5223 / \$ 36.00$

Copyright (c) 2021 by The American Association for Thoracic Surgery

https://doi.org/10.1016/j.jtcvs.2021.10.037
}

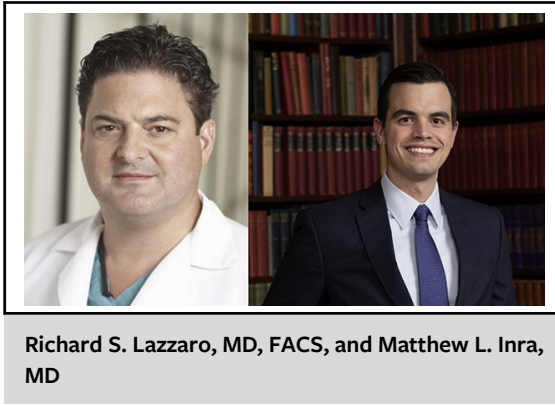

CENTRAL MESSAGE

A validated nomogram would help supplement clinical staging and its inherent inaccuracies, leading to better treatment decisions. Show me the money and validate this nomogram.

uptake value maximum of $>3.8$, histologic differentiation grade, tumor length $>25 \mathrm{~mm}$, and advanced $\mathrm{T}$ stage - that are associated with a pretreatment potential to predict the presence of occult lymph node metastases. In their cohort, the accuracy of staging T2 esophageal squamous cell carcinomas was $29.2 \%$, and $16.7 \%$ were understaged. ${ }^{4} \mathrm{~T} 2 \mathrm{~N} 0$ disease is an important clinical stage, because understaging these patients leads to incorrect treatment. Using the scoring system proposed, however, a patient with T2N0 disease may receive neoadjuvant treatment on the basis of lymph node metastasis risk score and a multidisciplinary decision, thereby negating the clinical staging inaccuracies.

External validation of Yun's nomogram has the potential to significantly affect guideline-directed treatment. T1 tumors are treated either endoscopically or surgically depending on depth of invasion and other risk characteristics. With this scoring system, however, a T1 tumor might have a high enough score to warrant significant concern for occult lymph node metastases. Endoscopic techniques are less morbid than open surgery and do not have the toxicity profiles of systemic therapy; if the risk is high enough for occult metastases, however, a multidisciplinary discussion should be had to decide whether guidelines should be followed or not, weighing the risk and benefit of a given treatment for each patient.

Nomograms can help us predict what was thought to be unpredictable. They are relevant and beneficial to clinical 
practice. Yun and colleagues revisit the limitations of current clinical staging in patients with esophageal squamous cell carcinoma and present a nomogram to predict occult lymph node metastases on the basis of tumor characteristics. A validated nomogram would help supplement clinical staging and its inherent inaccuracies, leading to better treatment decisions. Despite a nomograms ability to "predict the future," however, joint decision-making is just as important as it always was for patients with esophageal cancer. As with all treatment, there are risks and benefits. Consequently, the only future we want to predict next is the outcome resulting from external validation of Yun's nomogram because disease stage is the end all and be all when it comes to treatment for malignant disease. Show me the money and validate this nomogram.

\section{References}

1. Guo J, Wang Z, Qin J, Zhang H, Liu W, Zhao Y, et al. A prospective analysis of the diagnostic accuracy of 3 T MRI, CT and endoscopic ultrasound for preoperative T staging of potentially resectable esophageal cancer. Cancer Imaging. 2020;20:64.

2. Mehta K, Bianco V, Awais O, Luketich JD, Pennathur A. Minimally invasive staging of esophageal cancer. Ann Cardiothorac Surg. 2017;6:110-8.

3. Bergeron EJ, Lin J, Chang AC, Orringer MB, Reddy RM. Endoscopic ultrasound is inadequate to determine which T1/T2 esophageal tumors are candidates for endoluminal therapies. J Thorac Cardiovasc Surg. 2014;147:765-71.

4. Yun JK, Kim HR, Park SI, Kim Y-H. Risk prediction of occult lymph node metastasis in patients with clinical T1 through T2 N0 esophageal squamous cell carcinoma. J Thorac Cardiovasc Surg. 2022;164:265-75.e5. 